\title{
S wie Smartphone, SMS oder Sils Maria (und Birdman!)
}

\section{Dominik Heim}

PD Dr. med., Facharzt für Chirurgie

Das Smartphone - unser musikalischer Rückzugsort, die SMS-Maschine, unser Alltags-Fetisch, das «öffentliche» Telefon!

«Är isch lut, me ghört ne guet. Ja, er hät z'tue und s'loset alli, alli zu.» So treffend sieht Tinu Heiniger auf seiner neuen CD «Scho so lang» (2015) den TelefonAlltag im Zug. Die Szene endet im Totschlag! Das nerventötende Smartphone-Chaos im Zug von Kristen Stewart als Assistentin von Juliette Binoche im Film Sils Maria von Olivier Assayes (2014) dient der Einleitung zu einem leidenschaftlichen Kammerspiel eines alternden Filmstars in den Bergen des Engadins.

Das Smartphone, geliebtes, gehasstes, verhätscheltes Suchtobjekt, ist heute nicht nur Gebrauchsgegenstand, sondern verwirrendes Sinnbild einer digitalen Revolution geworden.

Wobei das Heute erst der Anfang sei und «nichts wird so bleiben, wie es war», und ob wir darauf eigentlich vorbereitet seien, fragte Dirk Helbling in der Sonntagszeitung (4.1.15). Der kommende Umbruch sei nämlich vergleichbar mit der industriellen Revolution vor 150 Jahren. Damals war die darauf folgende, soziale Antwort (rückblickend) erstaunlich logisch. Das neue Kranken- und Unfallversicherungsgesetz (KUVG) wurde eingeführt und mit der Gründung der Suva 1914 begann eine epochale Institution ihre Aktivität. Der damals an der Universität nur marginal gelesenen Traumatologie begegnete man 1912 mit der Gründung der Gesellschaft der Schweizer Unfallärzte. Später wurde daraus folgerichtig die Schweizerische Gesellschaft für Unfallmedizin und Berufskrankheiten SGUB, und nachdem die Berufskrankheiten ausgegliedert wurden, nannte man sich Schweizerische Gesellschaft für Traumatologie und Versicherungsmedizin SGTV. Und es gibt sie - beide - auch heute noch! Wie sieht die Antwort heute aus? Ganz an den digitalen Anfängen war man vielleicht noch versucht, das Mailen der Isabelle im Ärztesekretariat zu delegieren. Das schnelllebige Medienzeitalter erlaubte aber keine solchen arbeitszeitabhängigen Verzögerungen, Mailen wurde zur Gewohnheit. Ohne SMS zu kommunizieren ist aber Sakrileg und Facebook- und Twitterverweigerung ein No-Go! «I mean who are you? You hate bloggers. You make fun of Twitter. You don't even have a Facebook page. You're the one who doesn't exist», sagt Sam, Riggan Thomson's Tochter,

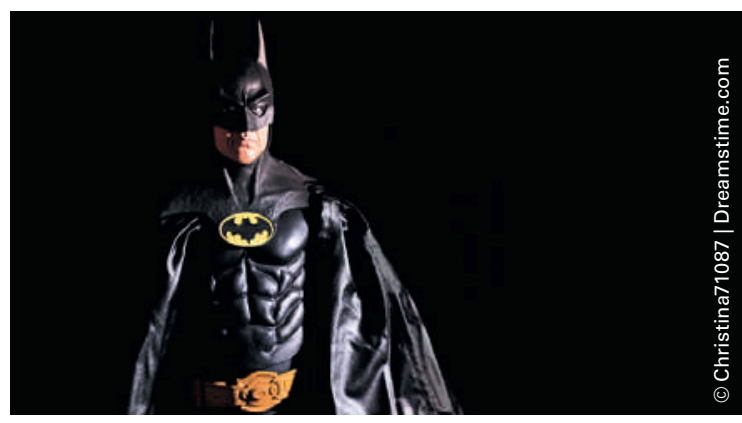

Batman, der Star aus den 80er Jahren.

zu ihrem Vater, dargestellt von Michael Keaton, im Film Birdman (2015). Und immerhin war Michael Keaton in den 8oer Jahren Batman! Im medizinischen Alltag haben wir uns also angepasst: Die selbst eingetippte elektronische Krankengeschichte entlastet jetzt das Sekretariat und belastet die gralsgehütete Arbeitszeit der Mediziner. Im Alltag beginnt unsere digitale Spur spätestens beim Bancomat (im Chirurgenalltag sprach man früher noch sarkastisch von einer «Blutspur»). So wird die Suche nach Anonymität heute zur logistischen Herausforderung, gänzlich blutleer zwar, aber wahrscheinlich unauslöschlich! Musikalisch können wir uns längst alles downloaden (medizinische Publikationen sowieso), wahrscheinlich wird zwar auch das digital irgendwo abgebildet. Aber die neue "Colosseum» (Time On Our Side, 2014) mit dem Booklet nach dem Kauf im ZigZag und einer kurzen Fachsimpelei mit "Wale» in den Händen zu halten, ist halt immer noch etwas Weihnachten. Und wenn Herbert Grönemeyer singt: «Wenn der harte Regen auf mich fällt - wasch ich mit ihm mein Gesicht» (Dauernd Jetzt, 2014), und wenn die Theaterkritikerin - in ihrer Verachtung für Hollywoodstars - Michael Keaton in Birdman ins Gesicht schleudert: "And I'm going to close your play. Would you like to know why? Because I hate you. And everyone you represent. Entitled. Spoiled. Selfish. Children. Blissfully untrained, unversed and unprepared to even attempt real art», dann sind die Emotionen immer noch da, digital auf Blu-ray oder - eben - very oldfashioned im Schallplatten-Laden und im Kino.

Auf dass uns verbale Eleganz (Grönemeyer), eloquentes Hollywooddrama (Birdman), scharfsinnige Nachdenklichkeit (Heiniger) und die Besinnlichkeit (Sils Maria) auch im digitalen Zeitalter erhalten bleiben! 